\title{
Cytokeratin 18 Fragment Measurement
}

National Cancer Institute

\section{Source}

National Cancer Institute. Cytokeratin 18 Fragment Measurement. NCI Thesaurus. Code C130160.

The determination of the amount of cytokeratin 18 fragment present in a sample. 